Virginia Commonwealth University VCU Scholars Compass

2014

\title{
18-Electron rule inspired Zintl-like ions composed of all transition metals
}

Jian Zhou

Virginia Commonwealth University, jzhou2@vcu.edu

Santanab Giri

Virginia Commonwealth University, sgiri@vcu.edu

Purusottam Jena

Virginia Commonwealth University, pjena@vcu.edu

Follow this and additional works at: http://scholarscompass.vcu.edu/phys_pubs

Part of the Physics Commons

(C) 2014 The Owner Societies. This is the author's version of a work that was accepted for publication in Physical Chemistry Chemical Physics, Vol. 16, Number 37, 20241-20247. The final publication is available at http://doi.org/ 10.1039/C4CP03141E

\section{Downloaded from}

http://scholarscompass.vcu.edu/phys_pubs/101

This Article is brought to you for free and open access by the Dept. of Physics at VCU Scholars Compass. It has been accepted for inclusion in Physics Publications by an authorized administrator of VCU Scholars Compass. For more information, please contact libcompass@vcu.edu. 


\title{
18-electron rule inspired Zintl-like ions composed of all transition metals
}

Jian Zhou, Santanab Giri, and Purusottam Jena*

Physics Department, Virginia Commonwealth University, Richmond, VA 23284 USA

\begin{abstract}
Zintl phase constitutes a unique class of compounds composed of metal cations and covalently bonded multiply charged cluster anions. Potential applications of these materials in solution chemistry and thermoelectric materials have given rise to renewed interest in the search of new Zintl ions. Up to now these are mostly composed of group 13, 14, and 15 post-transition metal elements and very few Zintl ions composed of all transition metal elements are known. Using gradient corrected density functional theory we show that the 18-electron rule can be applied to design a new class of Zintl-like ions composed of all transition metal atoms. We demonstrate this possibility by using Ti@ $\mathrm{Au}_{12}{ }^{2-}$ and $\mathrm{Ni} @ \mathrm{Au}_{6}{ }^{2-}$ di-anions as examples of Zintllike ions. Predictive capability of our approach is demonstrated by showing that $\mathrm{FeH}_{6}{ }^{4-}$ in already synthesized complex metal hydride, $\mathrm{Mg}_{2} \mathrm{FeH}_{6}$, is a Zintl-like ion, satisfying the 18electron rule. Our results open door to the design and synthesis of a new class of Zintl-like ions with potential for applications.
\end{abstract}

\footnotetext{
*Corresponding Author: pjena@ vcu.edu
} 
Zintl ions are multiply negatively charged polyatomic clusters belonging to post transition metal elements in group 13,14 , and 15 (e.g. $\mathrm{Sn}_{5}{ }^{2-}, \mathrm{Pb}_{5}{ }^{2-}, \mathrm{Pb}_{9}{ }^{4-}, \mathrm{Sb}_{7}{ }^{3-}, \mathrm{Bi}_{4}{ }^{2-}$, etc). ${ }^{1-3}$ When countered with positively charged alkali or alkaline-earth atoms, the Zintl ions form salts. However, unlike traditional intermetallics and semiconductors, the Zintl phase is characterized by significant bonding between the Zintl ions. Due to their unexpected stoichiometry and fascinating structures, Zintl ions have been studied since 1930s. ${ }^{4,5}$ Recent upsurge of research activity in Zintl ions is not only due to the observation that they can be extracted from the lattice and, when dissolved in appropriate solvents, can be used as reactants in solution chemistry, but also because they appear to be promising candidates for thermoelectric applications. For example, the cationic sites of the Zintl phase can be doped without strongly affecting the anionic network, thus allowing tailoring of the band gap. ${ }^{6}$ Similarly, the large and complex structures of the anion moieties lead to low thermal conductivity, enhancing the figure of merit of thermoelectric materials. ${ }^{6,7}$

The composition and stability of traditional Zintl ions have been rationalized by the electron counting rules originally proposed by Wade ${ }^{8,9}$ and later developed by Mingos ${ }^{10,11}$ for understanding the structure and bonding of polyhedral borane clusters $\left(\mathrm{B}_{n} \mathrm{H}_{m}\right)$. These species are considered to be electron deficient since they lack sufficient number of electrons for conventional covalent bonding between pairs of adjacent atoms. Thus, the concept of multicenter bonds was developed where valence electrons are separated into external and skeletal electrons. ${ }^{1}$ The external electrons are assumed to form covalent bonds with external ligands in polyhedral boranes or nonbonding electron pairs in post transition element clusters. The skeletal electrons, on the other hand, are responsible for cage bonding. According to the Wade-Mingos rules, $2 n+2,2 n+4$, and $2 n+6$ electrons are needed to form closo, nido, and archano boranes where $n$ is the number of vertices in the polyhedron, respectively. For example, in well-known icosahedral $\mathrm{B}_{12} \mathrm{H}_{12}{ }^{2-}$ cluster, two electrons from each of the $\mathrm{BH}$ pair form covalent bonds while the other two electrons are contributed to cage bonding. Thus, with $n=12$, there are 24 electrons that are available for cage bonding, but $2 n+2$ electron rule requires a total of $2 \times 12+2=26$ electrons for stabilizing the closo-structure. Hence, $\mathrm{B}_{12} \mathrm{H}_{12}$ requires two extra electrons to be stable and $\mathrm{B}_{12} \mathrm{H}_{12}{ }^{2-}$ exists as a di-anion. ${ }^{1}$ In group 14 and 15 elements one assumes that the two $\mathrm{s}$ electrons belong to the core and the $\mathrm{p}$ electrons form the valence shell. ${ }^{12}$ Thus, in $\mathrm{Sn}_{5}{ }^{2-}$ cluster there are $2 \times 5+2=12$ electrons and $\mathrm{Sn}_{5}{ }^{2-}$ has a closo-structure with a polyhedron having 5 
vertices. ${ }^{3}{\mathrm{In} \mathrm{Bi}_{4}}^{2-}$ there are $4 \times 3+2=14$ electrons and the cluster has the archano-structure $(2 \times 4+6$ = 14) with four vertices in the tetrahedron. Analogous to $\mathrm{B}_{12} \mathrm{H}_{12}{ }^{2-}$ cluster $\mathrm{Sn}_{12}{ }^{2-}$ also forms a closo-structure since $\mathrm{Sn}$ is isoelectronic with a $\mathrm{BH}$ pair and $\mathrm{Sn}_{12}{ }^{2-}$ is an example of a cage Zintl ion. $^{13}$

That the formation of Zintl ions in the gas phase could be inferred from photoionization mass spectral studies ${ }^{15}$ has led to a paradigm shift in the search for new Zintl ions. Farley and Castleman ${ }^{15}$ observed $\left(\mathrm{Na}_{4} \mathrm{Bi}_{3}\right)^{+}$as a magic number in the mass spectra of $\mathrm{Na}_{n} \mathrm{Bi}_{m}{ }^{+}$clusters and attributed its unusual stability to be due to the presence of $\mathrm{Bi}_{3}{ }^{3-}$ as a Zintl ion. A combination of photoelectron spectroscopy experiment and theoretical calculations has later identified the presence of Zintl ions $\mathrm{Sn}_{4}{ }^{4-}, \mathrm{Ga}_{4}{ }^{2-}, \mathrm{Sn}_{12}{ }^{2-}$, and $\mathrm{Pb}_{12}{ }^{2-}$ in cluster anions of $\left(\mathrm{Na}_{3} \mathrm{Sn}_{4}\right)^{-},\left(\mathrm{NaGa}_{4}\right)^{-}$, $\left(\mathrm{KSn}_{12}\right)^{-}$, and $\left(\mathrm{KPb}_{12}\right)^{-}$, respectively. ${ }^{16-19}$ The jellium electron counting rule ${ }^{20}$ originally developed to explain the magic numbers in alkali metal clusters ${ }^{21}$ has also been found to account for the stability of some Zintl ions. ${ }^{22,23}$ In the jellium model electrons fill a spherical potential well produced by a uniform distribution of positive ion cores and successive filling of $1 \mathrm{~S}^{2} 1 \mathrm{P}^{6}$ $1 \mathrm{D}^{10} 2 \mathrm{~S}^{2} 1 \mathrm{~F}^{14} 2 \mathrm{P}^{6} \ldots$ shells give rise to shell closings at 2, 8, 20, 34, 40, .. electrons. Bare clusters such as $\mathrm{In}_{11}{ }^{7-}$ and $\mathrm{Si}_{4}{ }^{4-}$ can be represented as Zintl ions where jellium electron counting rule prevails since they contain 40 and 20 electrons, respectively. ${ }^{22,23}$ Note that in the jellium model all the valence electrons are involved in skeletal bond formation. Recently, using photoelectron spectroscopy experiment and density functional theory calculations, Wang et al. showed that aluminum moieties within selected $\mathrm{Na}_{m} \mathrm{Al}_{n}{ }^{-}$clusters can also be classified as Zintl ions. ${ }^{24}$ This observation demonstrates that electron counting rules other than that due to Wade and Mingos can also be used to design and synthesize a new class of Zintl ions.

While much of the earlier work on Zintl ions has concentrated on traditional group 13 and 14 elements, during last decade a few endohedral clusters with transition metal (TM) atoms embedded inside post transition metal (PTM) cage skeletons have been experimentally synthesized (e.g. $\mathrm{Nb} @ \mathrm{As}_{8}{ }^{3-}, \mathrm{Pd}_{2} @ \mathrm{Sn}_{18}{ }^{4-}, \mathrm{Ni} @ \mathrm{~Pb}_{12}{ }^{2-}, \mathrm{Pt} @ \mathrm{~Pb}_{12}{ }^{2-}$, and $\left.\mathrm{Ir}_{0} \mathrm{Sn}_{12}{ }^{3-}\right) .{ }^{14,25-28}$ These findings further extend the elemental constitution of Zintl anions beyond pure PTM atoms to a combination of PTM atoms and TM atoms. While some these TM@ $\mathrm{PTM}_{n}{ }^{m-}(m>1)$ Zintl anions obey the Wade-Mingos rules, a few of them do not obey any electron counting rule. 
In this paper we raise a new question: can a Zintl-like ion composed of only transition metal atoms exist? If so, we may further enlarge the family of Zintl ions that could even be magnetic. Up to now, pure TM atom based Zintl ions are rare. This is because due to their low ionic potential energies, it is unusual for TM atoms to exhibit stable multiply negatively charged states. We note that the stability of compounds consisting of TM atoms is governed by the 18electron rule which requires the filling of $s^{2}, p^{6}$, and $d^{10}$ orbitals. Classic examples of compounds that obey the 18-electron rule are $\mathrm{Cr}\left(\mathrm{C}_{6} \mathrm{H}_{6}\right)_{2}, \mathrm{Fe}\left(\mathrm{C}_{5} \mathrm{H}_{5}\right)_{2}$, and $\mathrm{Au}_{12} \mathrm{~W} .{ }^{29,30}$ In the present study, we show that pure TM based moieties capable of attracting multiple electrons can be designed using the 18-electron rule and such negative ions can be identified with the Zintl-like ions. We confirm their charge state by counter balancing them with appropriate number of alkali or alkaline earth metal atoms. Using first-principles calculations we first show that experimentally synthesized $\mathrm{Mg}_{2} \mathrm{FeH}_{6}$ crystal $^{31,32}$ is characteristic of a Zintl phase material and the existence of $\mathrm{FeH}_{6}{ }^{4-}$ anion is consistent with the 18-electron rule. By replacing the $\mathrm{H}$ atoms to their isovalent $\mathrm{Au}$ atoms, forming a $\mathrm{Mg}_{2} \mathrm{FeAu}_{6}$ crystal, we find that the large electron transfer from $\mathrm{Mg}$ to $\mathrm{FeAu}_{6}$ moiety still persists. This suggests the possibility that Zintl-like ions composed of all TM metal atoms can be designed. We then show that the 18-electron rule can be used in general to guide the design and synthesis of Zintl-like ions composed of only TM atoms. By choosing $\mathrm{Na}$ atoms as counter cations we show that $\mathrm{Na}_{2}\left[\mathrm{Ti} @ \mathrm{Au}_{12}\right]$ and $\mathrm{Na}_{2}\left[\mathrm{Ni} @ \mathrm{Au}_{6}\right]$ moieties are stable. In addition, $\mathrm{Ti} @ \mathrm{Au}_{12}$ and $\mathrm{Ni} @ \mathrm{Au}_{6}$ carry doubly negative charge, exhibiting characteristics of Zintl ions. We further show that when $\mathrm{Na}_{2}\left[\mathrm{Ti} @ \mathrm{Au}_{12}\right]$ and $\mathrm{Mg}\left[\mathrm{Ti} @ \mathrm{Au}_{12}\right]$ are respectively assembled into twodimensional (2D) and one-dimensional (1D) periodic systems, their large charge transfer characters still remain. While the former is a semiconductor and non-magnetic, the latter is a metal and magnetic. Hence, the 2D Na $2\left[\mathrm{Ti} @ \mathrm{Au}_{12}\right]$ and 1D Mg[Ti@ $\left.\mathrm{Au}_{12}\right]$ constitute a novel TMbased Zintl phase. This observation opens the door to the synthesis of a new class of transition metal-based Zintl-like phases with unique properties. In the following we describe our theoretical methods and results.

We have used a multi-scale approach to study the TM-based Zintl-like ions. For the study of the Zintl-like phase in crystalline solid as well as in the gas phase we have used firstprinciples calculations based on spin polarized density functional theory (DFT) implemented in Vienna $A b$ initio Simulation Package (VASP). ${ }^{33}$ The exchange correlation energy is treated within the generalized gradient approximation (GGA) in the form proposed by Perdew, Burke, 
and Ernzerhof (PBE). ${ }^{34}$ The projected augmented wave (PAW) method ${ }^{35}$ with a cutoff energy of $300 \mathrm{eV}$ is used. For periodic systems, we use Monkhorst-Pack special k point meshes with grid density of $2 \pi \times 0.02 \AA^{-1}$ in their periodic directions to represent the reciprocal space. ${ }^{36}$ For the low dimensional $\mathrm{Na}_{2}\left[\mathrm{Ti} @ \mathrm{Au}_{12}\right], \mathrm{Mg}\left[\mathrm{Ti} @ \mathrm{Au}_{12}\right]$, and $\mathrm{Na}_{2}\left[\mathrm{Ni}_{0} @ \mathrm{Au}_{6}\right]$ systems, vacuum space of $15 \AA$ is applied along non-periodic directions. The reciprocal space is represented by the $\Gamma$ point. The geometric structures are optimized by conjugated gradient method without any symmetry constraints. Convergence criteria of total energy and Hellmann-Feynman force on each atom are set to $1 \times 10^{-4} \AA$ and $0.01 \mathrm{eV} / \AA$, respectively. Bader's charge analysis method is used in order to achieve reliable electron population. ${ }^{37}$

To test the sensitivity of our results to theoretical methods and approximations, some of the results on clusters obtained from VASP calculations were re-computed using Gaussian 09 program $^{38}$ at the DFT/B3LYP level of theory. For Cs, Ti, and Au we used Stuttgart/Dresden ECPs (SDD) basis sets while for Na we used $6-31+G(D)$ basis. The geometries were optimized without symmetry constraints. The forces and total energies were converged to $3 \times 10^{-4} \mathrm{eV} / \mathrm{A}$ and $1 \times 10^{-6} \mathrm{eV}$, respectively. The agreement between the results obtained from VASP and Gaussian 09 codes provides added confidence in the accuracy of our predictions.

The idea that the 18-electron rule can be used to design multiply negatively charged ions became apparent to us from recent work in complex hydrides which have been studied extensively for their potential to store large amounts of hydrogen. ${ }^{32}$ In particular we focus on two examples, $\mathrm{YMn}_{2} \mathrm{H}_{6}$ and $\mathrm{Mg}_{2} \mathrm{FeH}_{6}$. The former has been synthesized from the Lave-phase metal hydride $\mathrm{YMn}_{2} \mathrm{H}_{4.5}$ with gaseous hydrogen under moderate conditions. ${ }^{39}$ One of the two $\mathrm{Mn}$ atoms in $\mathrm{YMn}_{2} \mathrm{H}_{6}$ in the unit cell forms an octahedral pentavalent $\left[\mathrm{MnH}_{6}\right]^{5-}$ anion whose internal bonds are essentially covalent. Deficient five electrons are compensated by two cations, $\mathrm{Y}^{3+}$ and $\mathrm{Mn}^{2+}$. In $\mathrm{Mg}_{2} \mathrm{FeH}_{6}$ crystal, if one assumes that the bonding between $\mathrm{Fe}$ and $\mathrm{H}$ is covalent and that between $\mathrm{Mg}$ and $\mathrm{FeH}_{6}$ moiety is ionic, one would expect the charge on the $\mathrm{FeH}_{6}$ moiety to be -4 . Note that since Fe and Mn have, respectively, $3 d^{6} 4 s^{2}$ and $3 d^{5} 4 s^{2}$ configuration, the total number of electrons in both $\left[\mathrm{FeH}_{6}\right]^{4-}$ and $\left[\mathrm{MnH}_{6}\right]^{5-}$ are 18 and both the anions can be identified as Zintl-like anions. To confirm the charge state of $\mathrm{FeH}_{6}$, our first objective was to study the electronic structure of $\mathrm{Mg}_{2} \mathrm{FeH}_{6}$ crystal. We began with the lattice constant and initial ionic positions known from experiment ${ }^{31}$ and re-optimized the crystal structure using VASP code. 
After optimization, we find that the system retains its $F m-3 m$ symmetry space group (Figure 1a). In Figure $1 b$, we plot the difference electron density $\Delta \rho\left(=\rho_{\mathrm{Mg} 2 \mathrm{FeH} 6}-\rho_{\mathrm{Mg} 2}-\rho_{\mathrm{FeH} 6}\right)$ to visualize its electron distribution; positive and negative values represent electron accumulation and depletion, respectively. It can be clearly seen that the valence electrons of $\mathrm{Mg}$ atoms are transferred to the $\mathrm{FeH}_{6}$ moiety. This makes the $\mathrm{Mg}_{2} \mathrm{FeH}_{6}$ an ionically bonded crystal. Our band structure calculation also confirms that the $\mathrm{Mg}_{2} \mathrm{FeH}_{6}$ is a semiconductor with band gap of $1.9 \mathrm{eV}$ (Supporting Information, SI), consistent with previous calculations. In order to evaluate the charge state of each atom, we apply Bader's charge analysis. We find that on average each $\mathrm{Mg}$ atom loses 1.66 electrons, and each $\mathrm{H}(\mathrm{Fe})$ atom receives $0.52(0.21)$ electrons, making the electronic configuration of the system $\left[\mathrm{Mg}_{2}\right]^{+3.32}\left[\mathrm{FeH}_{6}\right]^{-3.32}$. This result is consistent with what can be derived from the 18 -electron rule and confirms that $\mathrm{FeH}_{6}{ }^{4-}$ is a stable TM-based Zintl-like ion.

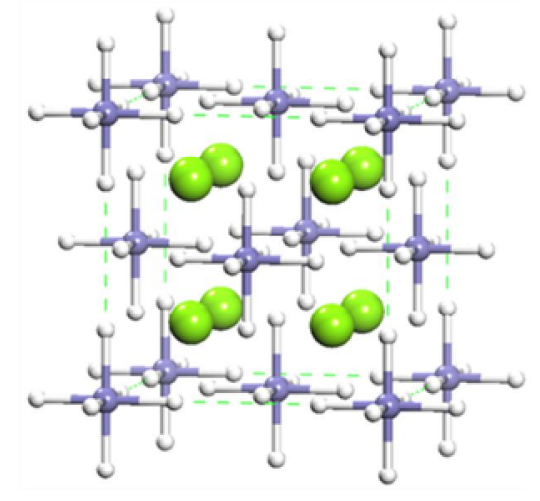

(a)

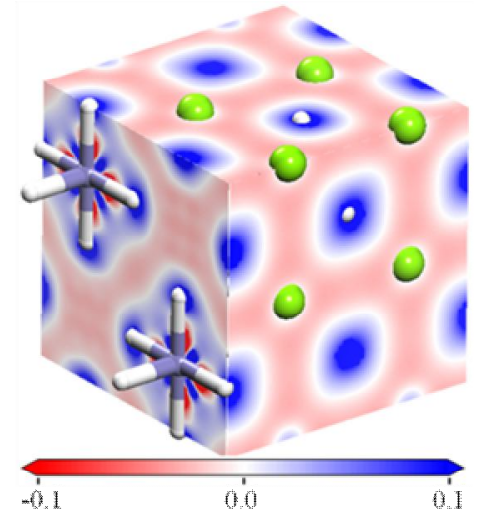

(b)

Figure 1. (a) Crystal structure and (b) difference electron density distribution, $\Delta \rho$ (in $2 \mathrm{D}$ slice form, e/ $\AA^{3}$ ) of $\mathrm{Mg}_{2} \mathrm{FeH}_{6}$ crystal; green, cyan, and white spheres represent $\mathrm{Mg}, \mathrm{Fe}$, and $\mathrm{H}$ atoms, respectively. Green dashed lines indicate unit cell considered in our simulation.

Since $\mathrm{H}$ and $\mathrm{Au}$ are isovalent and previous works have demonstrated that $\mathrm{Au}$ can mimic the properties of $\mathrm{H}$ in compounds [Ref.], we explored whether $[\mathrm{FeAu} 6]^{4-}$ could behave like a Zintl-like ion and if so can a crystal of $\mathrm{Mg}_{2}\left(\mathrm{FeAu}_{6}\right)$ be stabilized with $F m-3 m$ symmetry. We optimized the crystal structure of $\mathrm{Mg}_{2}\left(\mathrm{FeAu}_{6}\right)$ and found that it retains its $F m-3 m$ symmetry (Figure S2). Bader's charge analysis shows that the two $\mathrm{Mg}$ atoms transfer 3.08 electrons to the $\mathrm{FeAu}_{6}$ moiety, making the system $\left[\mathrm{Mg}_{2}\right]^{+3.08}\left[\mathrm{FeAu}_{6}\right]^{-3.08}$. This indicates that pure TM-based moiety can possess Zintl-like character, consistent with the expectation of the 18-electron rule. 
To see if the 18-electron rule can be generalized to yield Zintl-like ions composed of only transition metal atoms, we considered two endohedral clusters containing Au polyhedra. The first example we consider is $\mathrm{Ti} @ \mathrm{Au}_{12}$, where Ti is embedded inside an $\mathrm{Au}_{12}$ cage. In this cluster, each $\mathrm{Au}$ contributes one electron and $\mathrm{Ti}$, with electronic configuration $3 \mathrm{~d}^{2} 4 \mathrm{~s}^{2}$, contributes four valence electrons. Hence, in total there are 16 valence electrons and it needs two additional electrons to complete the 18-electron rule requirement. To find the ground state geometry of $\left[\mathrm{Ti} @ \mathrm{Au}_{12}\right]^{2-}$ we began with four isomers with symmetry point group $I_{h}, O_{h}, D_{5 h}$, and $D_{3 h}$ as starting points and optimized their structures without imposing symmetry constraints. The resulting optimized geometries are given in Figure 2. We found that $I_{h}$ isomer is stable among all other isomers and the isomer with $O_{h}$ symmetry lies $0.136 \mathrm{eV}$ higher in energy. To confirm that $I_{h}$ isomer is stable, we took two close isomers obtained from VASP result and re-optimized the structure using Gaussian 09 program. We found that $I_{h}$ is $0.12 \mathrm{eV}$ more stable than $O_{h}$ isomer, which is consistent with our VASP result. Since this energy difference is within the accuracy of the DFT/B3LYP level of theory, we calculated their IR and Raman spectra using the Gaussian 09 program. The results are given in Figure S3 (SI). Note that there is a marked difference between these spectra and can be compared with future experiments to determine the true ground state configuration.

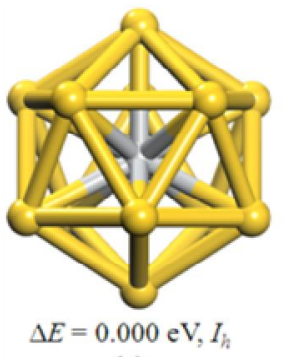

(a)

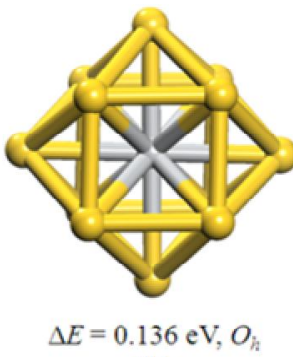

(b)

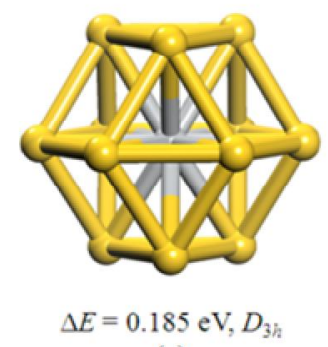

(c)

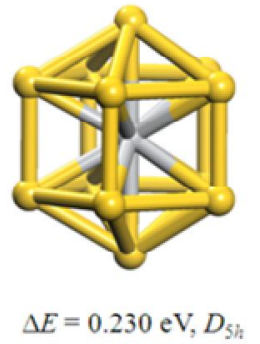

(d)

Figure 2. Optimized Geometries of four possible $\left[\mathrm{Ti} @ \mathrm{Au}_{12}\right]^{2-}$ isomers with relative energies.

To confirm that Ti@ $\mathrm{Au}_{12}$ cluster would prefer to exist as a di-anion, we computed the equilibrium structure, energetics, and electron charge density distribution of $\mathrm{Na}_{2}\left[\mathrm{Ti} @ \mathrm{Au}_{12}\right]$. Note that due to their electropositive character alkali atoms are known to donate their electron. We began with a structure of $\mathrm{Na}_{2}\left[\mathrm{Ti} @ \mathrm{Au}_{12}\right]$ by adding two $\mathrm{Na}$ atoms on the surface of $\mathrm{Ti} @ \mathrm{Au}_{12}$ neutral cluster. We considered four possible structures of $\mathrm{Ti} @ \mathrm{Au}_{12}$ (with symmetry point group 
of $I_{h}, O_{h}, D_{5 h}$, and $\left.D_{3 h}\right)$ described in the above as cores and attached two $\mathrm{Na}$ atoms on different sites. In this way, we generated more than 30 different isomers. After structural optimization, no imaginary frequencies were found for these relaxed isomers. The three energetically lowest structures are shown in Figure 3. From these isomers, we see that the $\mathrm{Na}$ atoms tend to reside on the hollow site of square $\mathrm{Au}$ facets. In the lowest energy isomer, the core Ti@ $\mathrm{Au}_{12}$ exhibit a symmetry point group of $O_{h}$, and two $\mathrm{Na}$ atoms reside on two opposite square facets. The average $\mathrm{Na}-\mathrm{Au}$ bond length in the relaxed configuration is $2.97 \AA$, and $\mathrm{Au}-\mathrm{Au}$ bond lengths lie between 2.77 and $2.85 \AA$. The symmetry point group of this $\mathrm{Na}_{2}\left[\mathrm{Ti} @ \mathrm{Au}_{12}\right]$ cluster is $D_{4 h}$. The second (third) lowest energy isomer, which are $0.059 \mathrm{eV}(0.061 \mathrm{eV})$ higher in energy than the ground state, is made up of $D_{5 h}\left(O_{h}\right)$ core Ti@ $\mathrm{Au}_{12}$ unit, with two $\mathrm{Na}$ atoms also residing on two square facets. Here also we took $D_{4 h}$ isomer of $\mathrm{Na}_{2}$ [Ti@ $\left.\mathrm{Au}_{12}\right]$ which has been found to be lowest energy isomer in VSAP optimization and re-optimized again in Gaussian 09. We found that the geometrical parameters are close to VASP results. For example Na-Au distance in Gaussian calculation is $2.97 \AA$ which is exactly same in VASP calculation. There are slight differences in other bond distances, but they lie within a range of $0.05 \AA$. So, for further discussion we only present results obtained from the VASP code.

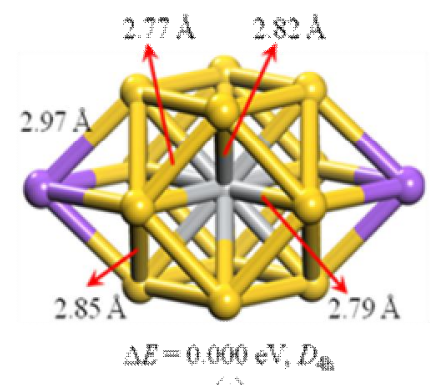

(ii)

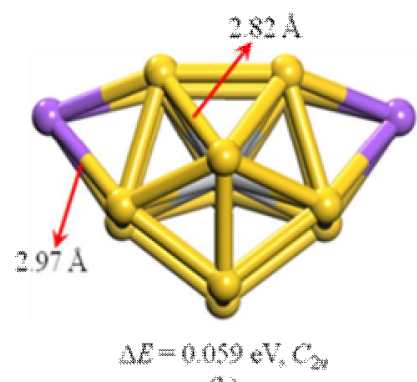

(b)

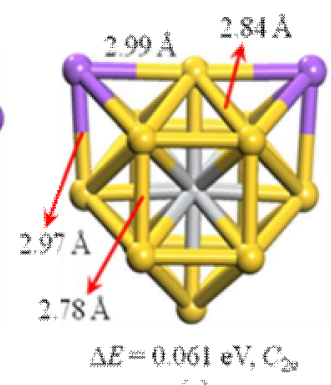

(c)

Figure 3. The three lowest energy isomers of $\mathrm{Na}_{2}\left[\mathrm{Ti} @ \mathrm{Au}_{12}\right]$ along with their relative energies $\Delta E$ and symmetry point groups. The yellow, magenta, and light grey spheres represent $\mathrm{Au}, \mathrm{Na}$, and $\mathrm{Ti}$, respectively. Some typical bond lengths are indicated by red arrows.

In Figure 4 we plot the difference electron density $\Delta \rho\left(=\rho_{\mathrm{Na} 2[\mathrm{Ti} @ \mathrm{Au} 12]}-\rho_{\mathrm{Na} 2}-\rho_{\mathrm{Ti} @ \mathrm{Au} 12}\right)$, which shows a large amount electron transfer from $\mathrm{Na}$ to the $\mathrm{Ti} @ \mathrm{Au}_{12}$ moiety. This is expected because the electron affinity of $\mathrm{Na}(0.548 \mathrm{eV})$ is much smaller than that of $\mathrm{Au}(2.309 \mathrm{eV}){ }^{40}$ Using Bader's charge analysis, we find that each $\mathrm{Na}$ atom donates 0.83 electrons. As for the eight $\mathrm{Au}$ atoms bonded to $\mathrm{Na}$, each of them receives $\sim 0.29$ electrons, and the other four $\mathrm{Au}$ 
atoms each receive $\sim 0.19$ electrons. The reason that the eight $\mathrm{Na}$-bonded $\mathrm{Au}$ atoms carry more electrons is because of attractive electrostatic interaction between the negatively charged $\mathrm{Au}$ and the positively charged $\mathrm{Na}$ atom. The interstitial $\mathrm{Ti}$ atom is also positively charged and loses 1.44 electrons. Hence, in total the $\mathrm{Ti} @ \mathrm{Au}_{12}$ moiety receives 1.66 electrons, making the electronic configuration of the system becomes $\left[\mathrm{Na}_{2}\right]^{+1.66}\left[\mathrm{Ti} @ \mathrm{Au}_{12}\right]^{-1.66}$. With this value, we demonstrate that the Ti@ $\mathrm{Au}_{12}$ moiety is a Zintl-like ion, consistent with the 18-electron rule. We note that for the other energetically lower isomers, the amount of charge transfer from the Na to the Ti@ $\mathrm{Au}_{12}$ moiety is also similar, which shows that its Zintl-like ion character is robust with respective to its geometric structure.

To further confirm that the preferred charge on Ti@ $\mathrm{Au}_{12}$ is -2 , we studied the relative stability of $\mathrm{Na}_{n}\left[\mathrm{Ti} @ \mathrm{Au}_{12}\right]$ clusters $(n=1,2,3)$ by calculating the energy gain is adding successive $\mathrm{Na}$ atoms, namely,

$$
\Delta E_{n}=E\left[\mathrm{Na}_{n-1} \mathrm{Ti} @ \mathrm{Au}_{12}\right]+E[\mathrm{Na}]-E\left[\mathrm{Na}_{n} \mathrm{Ti} @ \mathrm{Au}_{12}\right], n=1,2,3 .
$$

Here $E\left[\mathrm{Na}_{n} \mathrm{Ti} @ \mathrm{Au}_{12}\right]$ is the energy of the $\mathrm{Na}_{n}\left[\mathrm{Ti} @ \mathrm{Au}_{12}\right]$ cluster and $E[\mathrm{Na}]$ is the energy of the $\mathrm{Na}$ atom. The preferred charge state of $\mathrm{Ti} @ \mathrm{Au}_{12}$ can be obtained by determining which of the $\mathrm{Na}_{n}\left[\mathrm{Ti} @ \mathrm{Au}_{12}\right]$ clusters is the most stable and for that stoichiometry what is the charge on the Ti@ $\mathrm{Au}_{12}$ moiety. The computed values of $\Delta E_{n}$ are $2.56 \mathrm{eV}, 2.57 \mathrm{eV}$, and $1.42 \mathrm{eV}$ for $n=1,2$, and 3 , respectively. The abrupt drop in the binding energy of the third $\mathrm{Na}$ atom in $\mathrm{Na}_{n}\left[\mathrm{Ti}_{\mathrm{a}} @ \mathrm{Au}_{12}\right]$ clearly shows that the Ti@ $\mathrm{Au}_{12}$ moiety prefers to bind to two $\mathrm{Na}$ atoms. In other words, the preferred charge state of $\mathrm{Ti} @ \mathrm{Au}_{12}$ is -2 . Same conclusion can be reached by comparing the energies needed to dissociate $\mathrm{Na}_{2} \mathrm{Ti} @ \mathrm{Au}_{12}$ into $2 \mathrm{Na}^{+}+\mathrm{Ti} @ \mathrm{Au}_{12}{ }^{2-}$ or $\mathrm{Na}^{+}+\mathrm{NaTi} @ \mathrm{Au}_{12}$. These energies are respectively $12.65 \mathrm{eV}$ and $4.99 \mathrm{eV}$. The substantial stability of $\mathrm{Na}_{2}\left[\mathrm{Ti} @ \mathrm{Au}_{12}\right]$ where $\mathrm{Ti} @ \mathrm{Au}_{12}{ }^{2-}$ exists as a di-anion provides further proof that the latter is a Zintl-like ion. 


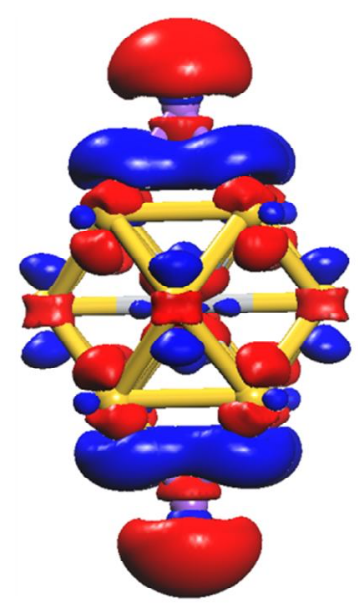

(a)

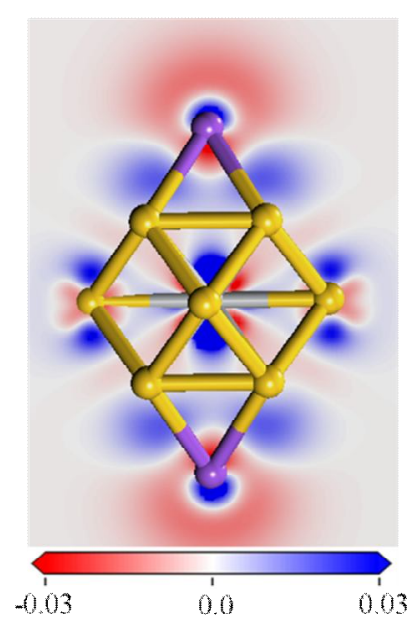

(b)

Figure 4. (a) Isosurface (with value of $0.01 \mathrm{e} / \AA^{3}$ ) and (b) 2D slice of electron difference density of $\mathrm{Na}_{2}\left[\mathrm{Ti} @ \mathrm{Au}_{12}\right]$. Blue and red colors indicate positive (electron accumulation) and negative (electron deficiency) values, respectively.

In order to further explore the electronic property of the $\mathrm{Na}_{2}\left[\mathrm{Ti} @ \mathrm{Au}_{12}\right]$ Zintl phase, we calculated its molecular orbital (MO) energy levels as shown in Figure 5. The energy gap between the highest occupied molecular orbital (HOMO) and the lowest unoccupied molecular orbital (LUMO) is $1.21 \mathrm{eV}$ at the GGA-PBE level of theory. By plotting the wave function of HOMO and LUMO orbital we find that the HOMO is singly degenerate and contributed by $\mathrm{Ti}$ and all $\mathrm{Au}$ atoms, while the LUMO is triply degenerate and arises from $\mathrm{Ti}, \mathrm{Na}$ as well as $\mathrm{Na}$ bonded Au atoms. This can be furthermore verified by the projected density of states (PDOS, see Figure S4 in SI). We clearly observe that the HOMO is hybridized mainly by the Au- $s$, Au- $d$, and the Ti- $d_{x y}$ orbitals, and the LUMO is contributed by hybridization among Au- $d, \mathrm{Au}-p, \mathrm{Na}-s$, and Ti- $d_{z 2}$ orbitals. 


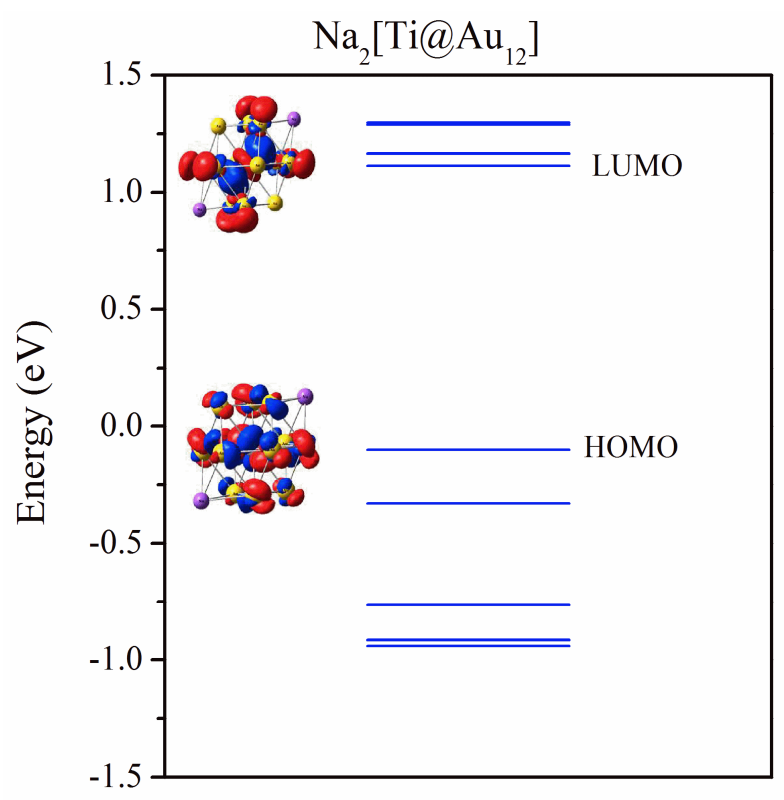

Figure 5. Molecular orbital energy levels and HOMO and LUMO wave functions of $\mathrm{Na}_{2}\left[\mathrm{Ti} @ \mathrm{Au}_{12}\right]$.

To study the effect of cation moieties on the Zintl-like characteristics of Ti@ $\mathrm{Au}_{12}{ }^{2-}$ we consider two other compensating cations, namely, $\mathrm{Cs}$ and $\mathrm{Mg}$. For $\mathrm{Cs}_{2}\left[\mathrm{Ti} @ \mathrm{Au}_{12}\right]$ we find that the lowest energy structure is similar to that of $\mathrm{Na}_{2}\left[\mathrm{Ti} @ \mathrm{Au}_{12}\right]$ where the two $\mathrm{Cs}$ atoms reside on two opposite square facets of the $O_{h} \mathrm{Ti} @ \mathrm{Au}_{12}$ cage (Figure S5 in SI). The symmetry point group of the $\mathrm{Cs}_{2}\left[\mathrm{Ti} @ \mathrm{Au}_{12}\right]$ is again $D_{4 h}$. Based on Bader's charge analysis, each Cs atom donates $\sim 0.82$ electrons, and hence the $\mathrm{Ti} @ \mathrm{Au}_{12}$ cage receives 1.64 electrons, forming $\left[\mathrm{Cs}_{2}\right]^{+1.64}\left[\mathrm{Ti} @ \mathrm{Au}_{12}\right]^{-1.64}$. Frontier molecular orbitals (HOMO and LUMO) of the $\mathrm{Cs}_{2}\left[\mathrm{Ti} @ \mathrm{Au}_{12}\right]$ are similar as that in $\mathrm{Na}_{2}\left[\mathrm{Ti} @ \mathrm{Au}_{12}\right]$ (Figure S7 in SI). For $\mathrm{Mg}\left[\mathrm{Ti} @ \mathrm{Au}_{12}\right]$, we find that $\mathrm{Mg}$ also prefers to reside on square facet of $\mathrm{Ti} @ \mathrm{Au}_{12}$ (Figure S6 in SI). Mg atom transfers 1.40 electrons to the $\mathrm{Ti} @ \mathrm{Au}_{12}$ moiety, making the system $\mathrm{Mg}^{+1.40}\left[\mathrm{Ti} @ \mathrm{Au}_{12}\right]^{-1.40}$. These results demonstrate that the Ti@ $\mathrm{Au}_{12}$ is, indeed, a Zintl-like ion, satisfying the 18-electron rule.

To substantiate our hypothesis that the 18-electron rule can be used in general to design TM-based Zintl-like ions, we consider another example, namely, $\mathrm{Ni} @ \mathrm{Au}_{6}$. Since the $\mathrm{Ni}\left(3 \mathrm{~d}^{8} 4 \mathrm{~s}^{2}\right)$

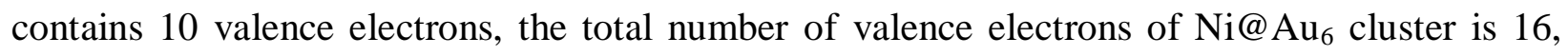
which again needs another two electrons to satisfy the 18-electron rule. Hence, we examine the geometric and electronic structure of $\mathrm{Na}_{2}\left[\mathrm{Ni} @ \mathrm{Au}_{6}\right]$. Various initial geometric structures are 
considered, and the lowest three energetic isomers are shown in Figure 6. We find that the ground state occurs when the two $\mathrm{Na}$ atoms reside on opposite sides of a distorted wheel-like $\mathrm{Ni} @ \mathrm{Au}_{6}$ cluster, and the $\mathrm{Na}-\mathrm{Au}$ bond lengths lie between $2.96 \AA$ and $3.09 \AA$. The symmetry point group is $C_{2}$. Bader's charge analysis reveals that each $\mathrm{Na}$ donates 0.83 electrons, so that the electronic configuration of this ground state structure becomes $\left[\mathrm{Na}_{2}\right]^{+1.66}\left[\mathrm{Ni} @ \mathrm{Au}_{6}\right]^{-1.66}$. The second lowest energy structure is higher than the ground state by $0.01 \mathrm{eV}$, where the two $\mathrm{Na}$ atoms reside on the same side of the $\mathrm{Ni@} \mathrm{Au}_{6}$ polyhedron and the symmetry point group is $C_{2 v}$. This energy difference corresponds to a temperature of $116 \mathrm{~K}$, indicating that this isomer can also been found experimentally. In this structure, each $\mathrm{Na}$ atom transfers $\sim 0.84$ electrons to the $\mathrm{Ni} @ \mathrm{Au}_{6}$ moiety, and the electronic configuration of this isomer is $\left[\mathrm{Na}_{2}\right]^{+1.68}\left[\mathrm{Ni} @ \mathrm{Au}_{6}\right]^{-1.68}$. Hence

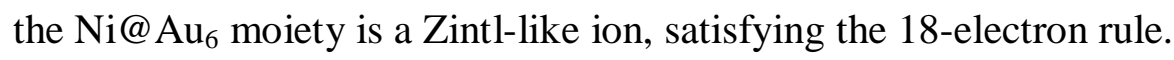

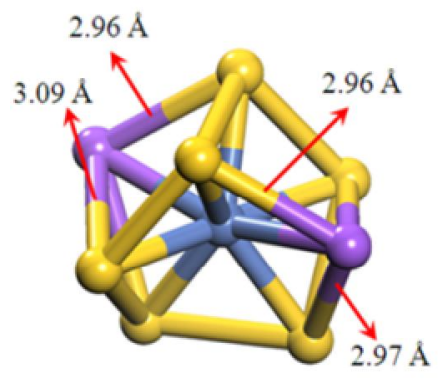

$\Delta E=0.000 \mathrm{eV}, C_{2}$

(a)

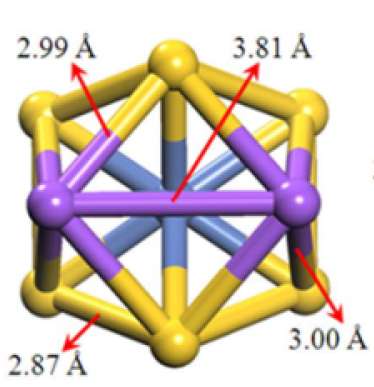

$\Delta E=0.010 \mathrm{eV}, C_{2 v}$

(b)

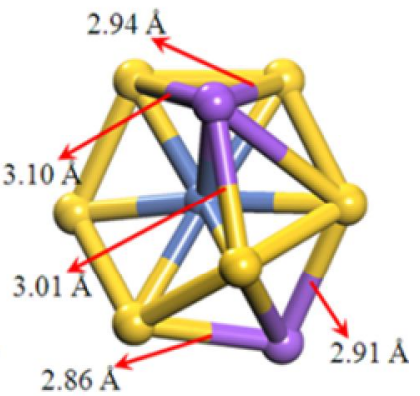

$\Delta E=0.273 \mathrm{eV}, C_{1}$

(c)

Figure 6. The three lowest energy isomers of $\mathrm{Na}_{2}\left[\mathrm{Ni} @ \mathrm{Au}_{6}\right]$ along with their relative energies $\Delta E$ and symmetry point group. The yellow, magenta, and dark blue spheres represent $\mathrm{Au}, \mathrm{Na}$, and $\mathrm{Ni}$, respectively.

In order to examine if the previous conclusion still holds in periodic systems, we designed a two-dimensional (2D) $\mathrm{Na}_{2}\left[\mathrm{Ti} @ \mathrm{Au}_{12}\right.$ s structure. Figure 7a shows the relaxed geometry, which is found to belong to $P 4 / \mathrm{mm}$ plane symmetry group. The bond length between the $\mathrm{Na}$ and the $\mathrm{Au}$ is $2.92 \AA$, a little shorter than in the cluster form. Bader's analysis shows each $\mathrm{Na}$ transfers 0.77 electrons to the $\mathrm{Ti} @ \mathrm{Au}_{12}$ moiety, confirming its Zintl-like character. Band structure calculation (Figure 7b) indicates that the 2D $\mathrm{Na}_{2}\left[\mathrm{Ti} @ \mathrm{Au}_{12}\right]$ is an indirect-gap semiconductor with band gap of $0.55 \mathrm{eV}$. The valence band maximum (VBM) and conductance band minimum $(\mathrm{CBM})$ are located at the $\mathrm{M}$ and $\Gamma$ point, respectively. 


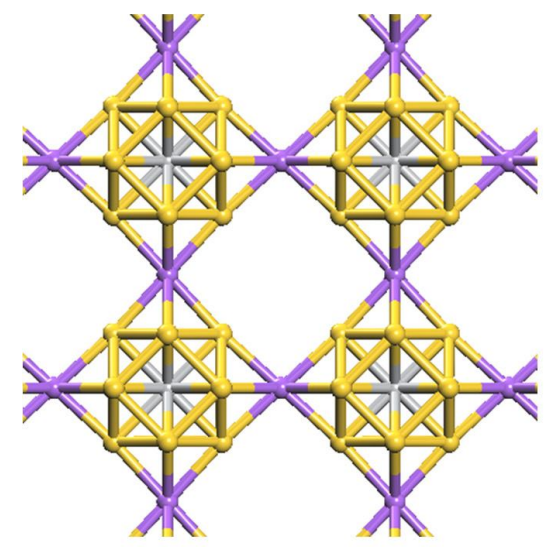

(a)

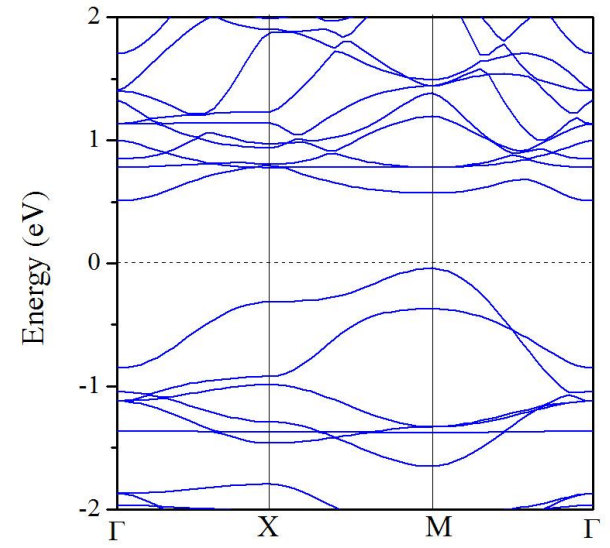

(b)

Figure 7. (a) Geometry and (b) band structure dispersion of $2 \mathrm{D} \mathrm{Na}_{2}\left[\mathrm{Ti} @ \mathrm{Au}_{12}\right]$.

For a periodic $\mathrm{Mg}\left[\mathrm{Ti} @ \mathrm{Au}_{12}\right]$ Zintl-like phase, we consider a one dimensional (1D) periodic chain. The relaxed structure is shown in Figure 8a. We see that the Au atoms in different $\mathrm{Ti} @ \mathrm{Au}_{12}$ moieties are bonded together. Charge analysis shows that each $\mathrm{Mg}$ donates 1.79 electrons to each $\mathrm{Ti} @ \mathrm{Au}_{12}$. We find that the Ti atoms are magnetic carrying a moment of $0.66 \mu_{\mathrm{B}}$, contributed primarily by their $\mathrm{d}_{z 2}$ orbitals (Figure $8 \mathrm{~b}$ ). Ferromagnetic coupling between the Ti atoms is calculated to be more stable than antiferromagnetic coupling by $0.025 \mathrm{eV}$ per unit cell, which corresponds to a temperature of $290 \mathrm{~K}$. We attribute the ferromagnetic coupling to hybridization between the Au- $s$ and Ti- $d$ orbitals. Band dispersions of both spin up and spin down channels are also plotted (Figure 8c) showing that the 1D $\mathrm{Mg}\left[\mathrm{Ti} @ \mathrm{Au}_{12}\right]$ chain is metallic in both spin channels. Since conventional Zintl phase materials are semiconducting and paramagnetic, the magnetic and metallic properties of $1 \mathrm{D} \mathrm{Mg}\left[\mathrm{Ti} @ \mathrm{Au}_{12}\right]$ are abnormal. The reason is that the anionic moieties, $\mathrm{Ti} @ \mathrm{Au}_{12}$, are bonded together, instead of separated by alkali or alkaline-earth metal atoms as is the case in conventional Zintl phases. 


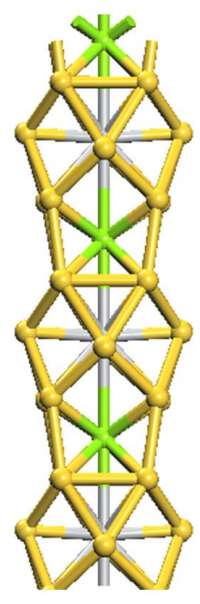

(a)

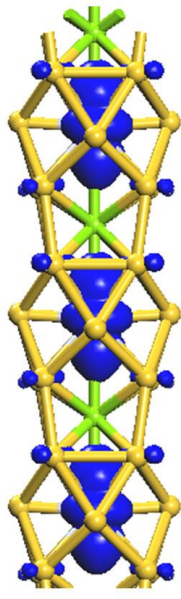

(b)

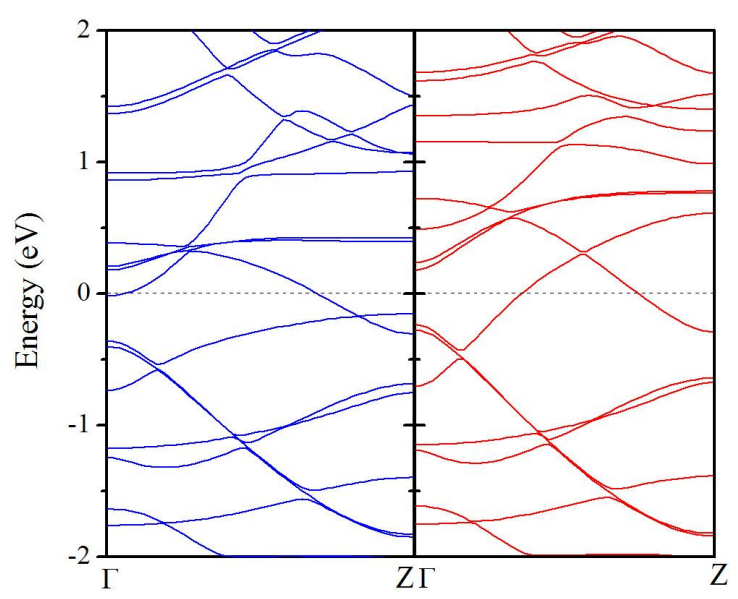

(c)

Figure 8. (a) Geometry, (b) spin density (isosurface value of $0.01 \mathrm{e} / \AA^{3}$ ), and (c) band structure of 1D Mg[Ti@ $\left.\mathrm{Au}_{12}\right]$. Blue and red curves in the band structure plot represent spin up and spin down channel, respectively.

In summary, we show for the first time that Zintl-like ions composed of only TM atoms can be realized by using the 18-electron rule. This is demonstrated by first performing the Bader's charge analysis in complex metal hydride, $\mathrm{Mg}_{2} \mathrm{FeH}_{6}$. First principle calculations based on gradient corrected density functional theory are further carried out to generalize the merit of using the 18-electron rule in the design of transition metal-based Zintl-like anions by focusing on $\mathrm{Na}_{2}\left[\mathrm{Ti} @ \mathrm{Au}_{12}\right], \mathrm{Mg}\left[\mathrm{Ti} @ \mathrm{Au}_{12}\right], \mathrm{Cs}_{2}\left[\mathrm{Ti} @ \mathrm{Au}_{12}\right]$, and $\mathrm{Na}_{2}\left[\mathrm{Ni} @ \mathrm{Au}_{6}\right]$ clusters. These are shown to be very stable with ionic bonding between the cationic $\left(\mathrm{Na}^{+}, \mathrm{Cs}^{+}, \mathrm{Mg}^{2+}\right)$ and anionic components ( $\mathrm{Ti} @ \mathrm{Au}_{12}{ }^{2-}, \mathrm{Ni} @ \mathrm{Au}_{6}{ }^{2-}$ ). Bader's charge analysis further shows that these anionic components are di-anions making Ti@ $\mathrm{Au}_{12}{ }^{2-}$ and $\mathrm{Ni} @ \mathrm{Au}_{6}{ }^{2-}$ candidates for forming the Zintl-like phase. This is demonstrated by constructing $2 \mathrm{D}$ and $1 \mathrm{D}$ periodic structures of $\mathrm{Na}_{2}\left[\mathrm{Ti} @ \mathrm{Au}_{12}\right]$ and $\mathrm{Mg}\left[\mathrm{Ti} @ \mathrm{Au}_{12}\right]$. The former is found to be a nonmagnetic semiconductor while the latter is a ferromagnetic metal. That the 18-electron rule can be used to design Zintl-like ions composed of only TM atoms furthers the scope of the Zintl ions and opens the door to the synthesis of new Zintl phase compounds. Periodic structures formed from these Zintl-like transition metal moieties exhibit unique electronic and magnetic properties. The ability to tailor the cationic and anionic components of the Zintl salts may have potential applications in solution chemistry as well as in thermoelectric materials. 
Electronic supplementary information (ESI) available: Band structure of $\mathrm{Mg}_{2} \mathrm{FeH}_{6}$, structure of $\mathrm{Mg}_{2} \mathrm{FeAu}_{6}, \mathrm{IR}$ and Raman spectra of [Ti@ $\left.\mathrm{Au}_{12}\right]^{2-}$, PDOS of $\mathrm{Na}_{2}\left[\mathrm{Ti} @ \mathrm{Au}_{12}\right]$, molecular orbitals of $\mathrm{Cs}_{2}\left[\mathrm{Ti} @ \mathrm{Au}_{12}\right]$ and isomers of $\mathrm{Cs}_{2}\left[\mathrm{Ti}_{0} @ \mathrm{Au}_{12}\right]$ and $\mathrm{Mg}\left[\mathrm{Ti} @ \mathrm{Au}_{12}\right]$.

\section{ACKNOWLEDGMENT}

Research was supported by the U.S. Department of Energy, Office of Basic Energy Sciences, Division of Materials Sciences and Engineering under Award \# DE-FG02-96ER45579. We also acknowledge resources of the National Energy Research Scientific Computing Center, which is supported by the Office of Science of the U.S. Department of Energy under Contract No. DE-AC02-05CH11231.

\section{REFERENCES}

(1) T. F. Fässler, Zintl Phases: Principles and Recent Developments; Springer: Heidelberg, 2011.

(2) S. Scharfe, F. Kraus, S. Stegmaier, A. Schier and T. F. Fässler, Angew. Chem. Int. Ed. 2011, 50, 3630 .

(3) J. D. Corbett, Chem. Rev. 1905, 85, 383.

(4) E. Zintl, J. Goubeau and W. Dullenkopf, Z. Phys. Chem. Abt. A 1931, 154, 1.

(5) E. Zintl and H. Z. Kaiser, Anorg. Allgem. Chem. 1933, 211, 113.

(6) L. Zhang, M.-H. Du and D. J. Singh, Phys. Rev. B 2010, 81, 075117.

(7) S. M. Kauzlarich, S. R. Brown and G. J. Snyder, Dalton Trans. 2007, 2099.

(8) K. Wade, Chem. Commun. 1971, 792.

(9) K. Wade, Adv. Inorg. Chem. Radiochem. 1976, 18, 1. 
(10) D. M. P. Mingos, Acc. Chem. Res. 1984, 17, 311.

(11) D. M. P. Mingos and R. L. Johnston, Struct. Bond. 1987, 68, 29.

(12) R. G. Wheeler, W. L. LaiHing, W. L. Wilson and M. A. Duncan, J. Chem. Phys. 1988, 88, 2831.

(13) N. Shao, S. Bulusu and X. C. Zeng, J. Chem. Phys. 2008, 128, 154326.

(14) Z.-M. Sun, H. Xiao, J. Li and L.-S. Wang, J. Am. Chem. Soc. 2007, 129, 9560.

(15) R. W. Farley and A. W. Castleman Jr., J. Am. Chem. Soc. 1989, 111 , 2734.

(16) W. J. Zheng, O. C. Thomas, J. M. Nilles, K. H. Bowen, A. C. Reber and S. N. Khanna, J. Chem. Phys. 2011, 134, 224307.

(17) A. E. Kuznetsov, A. I. Boldyrev, X. Li and L. S. Wang, J. Am. Chem. Soc. 2001, 123, 8825.

(18) L. F. Cui, X. Huang, L. M. Wang, D. Y. Zubarev, A. I. Boldyrev, J. Li and L. S. Wang, J. Am. Chem. Soc. 2006, 128, 8390.

(19) L. F. Cui, X. Huang, L. M. Wang, J. Li and L. S. Wang, J. Phys. Chem. A 2006, 110, 10169.

(20) M. Brack, Rev. Mod. Phys. 1993, 65, 677.

(21) W. D. Knight, K. Clemenger, W. A. de Heer, W. A. Saunders, M. Y. Chou and M. Cohen, Phys. Rev. Lett. 1984, 52, 2141.

(22) S. C. Sevov and J. D. Corbett, Inorg. Chem. 1991, 30, 4877.

(23) T. Goebel, Y. Prots and F. Haarmann, Z. Kristallogr. New Cryst. Struct. 2008, $223,187$.

(24) H. Wang, X. Zhang, Y. J. Ko, A. Grubisic, X. Li, G. Ganteför, H. Schnöckel, B. W. Eichhorn, M. S. Lee, P. Jena, A. K. Kandalam, B. Kiran and K. H. Bowen, J. Chem. Phys. 2014, 140, 054301.

(25) H.-G. von Schnering, J. Wolf, D. Weber, R. Ramirez and T. Meyer, Angew. Chem. Int. Ed. 1986, 25, 353. 
(26) E. N. Esenturk, J. Fettinger and B. Eichhorn, J. Am. Chem. Soc. 2006, 128, 9178.

(27) E. N. Esenturk, J. Fettinger, Y.-F. Lam and B. Eichhorn, Angew. Chem. Int. Ed. 2004, 43, 2132.

(28) J.-Q. Wang, S. Stegmaier, B. Wahl and T. F. Fässler, Chem. Eur. J. 2010, 16, 1793.

(29) P. Pyykkö, J. Organ. Chem. 2006, 691, 4336.

(30) X. Li, B. Kiran, J. Li, H.-J. Zhai and L.-S. Wang, Angew. Chem. Int. Ed. 2002, 41, 4786.

(31) J.-J. Didisheim, P. Zolliker, K. Yvon, P. Fischer, J. Schefer, M. Gubelmann and A. F. Williams, Inorg. Chem. 1984, 23, 1953.

(32) K. Miwa, S. Takagi, M. Matsuo and S. Orimo, J. Phys. Chem. C 2013, 117, 8014.

(33) G. Kresse and J. Furthmüller, Phys. Rev. B 1996, 54, 11169.

(34) J. P. Perdew, K. Burke and M. Ernzerhof, Phys. Rev. Lett. 1996, 77, 3865.

(35) P. E. Blöchl, Phys. Rev. B 1994, 50, 17953.

(36) H. J. Monkhorst and J. D. Pack, Phys. Rev. B 1976, 13, 5188.

(37) W. Tang, E. Sanville and G. Henkelman, J. Phys.: Condens. Matter 2009, 21, 084204.

(38) M. J. Frisch, G. W. Trucks, H. B. Schlegel, et al., GAUSSIAN 09, Revision B.01, Gaussian, Inc., Wallingford, CT, 2010.

(39) M. Matsuo, K. Miwa, S. Semboshi, H.-W. Li, M. Kano and S. Orimo, Appl. Phys. Lett. 2011, 98, 221908.

(40) J. A. Dean, Lange's Handbook of Chemistry, 15th Ed.; McGraw-Hill: New York, 1999. 